\title{
ON THE PREDICTIVE CONTENT OF PRODUCTION SURVEYS: \\ A PAN-EUROPEAN STUDY
}

Aurélie Lemmens ${ }^{1 \dagger}$, Christophe Croux $^{\dagger}$ and Marnik G. Dekimpe ${ }^{\dagger \dagger}$

${ }^{\dagger}$ Department of Applied Economics, K.U.Leuven, Belgium

${ }^{\ddagger}$ Faculty of Business Administration, Erasmus University

Rotterdam, The Netherlands

June 11, 2004

${ }^{1}$ Corresponding author. Phone: +32-16-326960; Fax: +32-16-326732. Naamsestraat 69, B-3000 Leuven, Belgium. Email: aurelie.lemmens@econ.kuleuven.ac.be. 


\begin{abstract}
For over forty years, Business Tendency Surveys have been collected in multiple member states of the European Union. Previous research has studied the predictive content of the expectation variables included in those surveys through bivariate, within-country, Granger-causality tests, which has resulted in mixed conclusions. We extend previous research in various ways, as we (i) explicitly allow for cross-country influences, and (ii) do so using both bivariate and multivariate Granger-causality tests. Specifically, the multivariate El Himdi - Roy test is adapted to jointly test the forecasting value of multiple production expectation series, to assess whether part of this joint effect is indeed due to cross-country influences, and to determine which countries' expectation series have most "clout" in predicting the production levels in the other member countries, or have highest "receptivity", in that their production levels are Granger caused by the other countries' expectations.
\end{abstract}

KEYWORDS: Business surveys, Cross-correlations, Production Expectations, Granger Causality. 


\section{INTRODUCTION}

For over forty years, Business Tendency Surveys have been collected by the European Union in the framework of the Joint Harmonised EU Programme of Business and Consumer Surveys. The Programme was initially set up in 1961 by the European Commission, and currently includes the fifteen member states of the European Union. Business Surveys are carried out on a monthly basis by various public and private institutions in the respective member countries. The presentation, methods and questions of the Business Tendency Surveys are harmonised across countries according to EU guidelines. We refer to "The Joint Harmonised EU Programme of Business and Consumer Surveys User Guide 2002" of the European Commission, Directorate General Economic and Financial Affairs, Economic Studies and Research, Business Surveys for more detailed information on how these surveys are implemented. Two kinds of attitudinal data are collected: (i) "Judgments" (JUD), an assessment of the current or past status of a given variable, and (ii) "Expectations" (EXP), an estimation of the likely future status of that variable. These two types of attitudinal information are collected for five key components of the economy: Industry, Construction, Consumers, Retail Trade and Services. In this study, we focus on an industry-related indicator, the Production Expectations (PEXP).

The sample size for each survey varies across countries according to their population size. Each month, almost 68,000 companies and 27,000 consumers across the European Union are currently surveyed. Not surprisingly, Business Surveys are both expensive and time-consuming. For example, the cost in 2003 for the European Commission of the Harmonised Joint EU Programme of Business and Consumer Surveys amounted to slightly over 4.5 million euros. This figure does not yet incorporate the costs incurred by the respective national institutions that carry out the actual surveys. The latter are estimated to be another 6 to 7 million euros. These costs are often justified on the basis that they represent an early source of information for politicians, economists, 
researchers, senior executives and/or media. Indeed, the survey data become publicly available on the last day of each month, whereas Account data $(A C C)$ - i.e. the actual, objectively measured, levels of a variable - are generally published only two to four months later (Buffeteau and Mora, 2000). However, timeliness is not a sufficient justification for the continued use of such expensive surveys. They should also prove to have some predictive content regarding actual $A C C$ data: if Business Tendency Surveys cannot be used as relevant predictors for the future state of the economy, there is no point using them for economic surveillance.

The performance of the PEXP series will be measured by studying whether these can improve forecasts of future Production Accounts $(P A C C)$ that are exclusively based on the past of the $P A C C$ series. More precisely, we will investigate whether the variance of the error in forecasting future values of the $P A C C$, using an (optimal) forecast based on the observed values of both $P A C C$ and PEXP series is strictly smaller than the variance of the prediction error, using an (optimal) forecast only based on the observed values of the $P A C C$ series. If this is the case, we may conclude that PEXP series Granger causes the $P A C C$ series (Granger, 1969). In this paper, the "predictive content" always refers to this notion of Granger causality.

The predictive content of Business Surveys has already been investigated in a substantive number of studies. Most of these were based on Scandinavian countries. Bergström (1995) and Teräsvirta (1986) explored the relationship between the PACC series and a number of barometer (Business Survey) series using regression models in, respectively, Sweden and Finland. Lindström (2000) extended these analyses by examining the short-term forecasting value of Business Surveys for predicting the volume of manufacturing output growth in Sweden up to 1998. Christoffersson, Roberts and Eriksson (1992) used a frequency domain analysis to investigate the relationship between $P A C C$ and Business Survey series of total manufacturing in Sweden. Öller and Tallbom (1996) applied an extended Kalman filter on the Business Survey series. The 
general picture obtained from these earlier studies is that Business Survey variables have predictive content in explaining future $P A C C$ series, at least in the considered Scandinavian countries. Hanssens and Vanden Abeele (1987), on the other hand, studied the predictive content of PEXP for Belgium, France, Germany, The Netherlands and Italy. Using bivariate Granger-causality tests, they found that the inclusion of PEXP did not systematically improve the forecasting performance of simple univariate time-series extrapolations of the $P A C C$ series. Hence, previous research ended in mixed results, and the question on the predictive value of Business Tendency Surveys remains open. We will contribute to this ongoing debate in a number of ways.

First, the existing literature focused on a limited subset of countries, ranging from one (e.g. Bergström, 1995 and Lindström, 2000) to five (Hanssens and Vanden Abeele, 1987) states. Our analysis, in contrast, uses data of more than ten countries (see Section 3). Moreover, by using information that has just become publicly available, we are able to extend the end date of the analysis from, respectively, 1983 (Teräsvirta, 1986; Hanssens and Vanden Abeele, 1987) and 1998 (Lindström, 2000) to December 2002.

Second, unlike previous studies, we will take potential cross-country relationships into account. Previous studies only allowed for a within-country relationship, checking, for example, whether the French PEXP proved useful in predicting France's own future $P A C C$ series. We extend the scope of this investigation by testing whether also the $P E X P$ in other countries have information value in predicting the future evolution of the French $P A C C$ series. Such cross-country influences may well exist among the various EU countries as the free transfer of ideas, products and technologies among them is increasingly facilitated (Mahajan and Muller, 1994), resulting in both cross-country word-of-mouth effects (Tellis et al, 2003) and considerable trade among the various member states, as reflected in an intra-EU15 trade/GDP ratio of over 16\% (Eurostat, 1999). Because of this economic interdependence, industrial optimism/pessimism in one country, as reflected in the evolution of its $P E X P$, may well affect the $P A C C$ in 
another country. Cross-country linkages was also found by Artis and Zhang (1997, 1999) concerning economic activity.

The aforementioned cross-country effects could be investigated through a sequence of bivariate tests. For example, bivariate Granger-causality tests could be implemented to assess whether PEXP in country $X$ affects future $P A C C$ levels in country $Y$. However, as the number of EU countries increases, the number of tests required to cover all possible combinations would rapidly become excessive, causing the individual $p$-values to suffer from the well-known multiple-testing problem. As a third contribution, we will therefore apply the multivariate test procedure introduced by El Himdi and Roy (1996). Through this procedure, we will first investigate the general predictive content of the collection of all PEXP series vis-à-vis the collection of all PACC series. This joint Granger-causality test will offer a more powerful test on the predictive value of the ambitious European Union's Business Survey plan than a sequence of bivariate tests.

Next, we will adjust the El Himdi - Roy test statistic to answer three key questions of interest:

- Can we attribute part of this "general causality" to cross-country influences?

- Are there some countries whose PEXP are more informative than others for the future evolution of the $P A C C$ in other countries? Such countries will be denoted as having a lot of "clout". Referring to the notion of asymmetry developed in the market-share literature (Cooper and Nakanishi, 1998, pp.56-57), "clout" is the ability of a brand or company to influence the other players (i.e. brands or firms) in a specific market, and consequently shape the demand and competition in that market. Similarly, in the context of PEXP, we denote by "clout" the ability of a country to Granger cause the future production level of other countries. For example, Sensier et al. (2004) attributed such "clout" to Germany, 
whose composite leading indicator has a particularly marked effect on the Italian economy.

- Are there countries whose $P A C C$ series is more predictable (than others) by other countries' PEXP series, and whose economy therefore seems to be more "receptive" (see Cooper and Nakanishi (1998, pp.56-57) for a conceptually similar use of the term in the market-share attraction literature) to changes in other countries' economic climate (as reflected in their respective PEXP series)?

Answering these questions should provide new insights into the economic interdependencies among the various member states of the European Union in general, and more specifically, on the relative forecasting value of the Business Tendency Surveys undertaken in these countries.

\section{METHODOLOGY}

In line with existing literature (see e.g. Hanssens and Vanden Abeele, 1987), we adopt the notion of Granger causality between PEXP and future PACC to assess the predictive value of the Business Tendency Surveys' PEXP series. Unlike previous studies, however, we will conduct the analysis at various levels. First, in Section 2.1, we describe the bivariate Haugh (1976) test. The Haugh test will make it feasible to determine (i) whether the PEXP series in country $i(i=1, \ldots, d$ where $d$ is the number of considered countries) Granger causes the $P A C C$ series in that same country, and (ii) whether PEXP in country $i$ Granger causes the $P A C C$ in country $j$. Next, in Section 2.2, we review the multivariate El Himdi - Roy (1997) test so as to allow to quantify the combined predictive content of all PEXP series, considering all countries together. We subsequently modify the El Himdi - Roy statistic to determine whether part of this combined predictive value can be attributed to cross-country influences. Finally, we propose two further modifications to quantify (i) which countries' PEXP 
series are the most informative as to the future $P A C C$ levels in other countries, i.e. have most "clout", and (ii) which countries' PACC series are most predictable through other countries' PEXP, i.e. have a higher "receptivity".

We denote $P A C C$ in country $i$ at time $t$ by $Y_{i t}$, and use $X_{i t}$ to denote the surveyed PEXP made at $t$ about the future production level in country $i$. Each of the aforementioned tests requires stationarity of the series under investigation. In line with prior studies (see e.g. Hanssens and Vanden Abeele, 1987; Öller and Tallbom, 1996), it was found, by carrying out various (unreported) stationarity tests, that all PEXP series $\left(X_{i t}\right)$ were already stationary, while the $P A C C$ series $\left(Y_{i t}\right)$ required seasonal differencing of order $12\left(\nabla^{12} Y_{i t}=Y_{i t}-Y_{i t-12}\right)$ to achieve stationarity.

\subsection{Causality tests based on bivariate cross-correlations}

For the bivariate test in country $i$, both time series, $X_{i t}$ and $\nabla^{12} Y_{i t}$, are first modelled as a univariate ARMA process, i.e.

$$
\begin{aligned}
\Phi^{x}(L) X_{i t} & =C^{x}+\Theta^{x}(L) u_{i t} \\
\Phi^{y}(L) \nabla^{12} Y_{i t} & =C^{y}+\Theta^{y}(L) v_{i t}
\end{aligned}
$$

where $\Phi^{x}(L)$ and $\Phi^{y}(L)$ are autoregressive polynomials, $\Theta^{x}(L)$ and $\Theta^{y}(L)$ movingaverage polynomials, and $C^{x}$ and $C^{y}$ the deterministic components (here, constant terms). After filtering the series with the above ARMA models, we obtain estimated innovation series $\hat{u}_{i t}$ and $\hat{v}_{i t}$, which can be regarded as white-noise processes with zero mean, but possibly correlated with each other at different leads and lags.

If we consider both series of innovations, $u_{i t}$ and $v_{i t}$, it is well known (see e.g. Gouriéroux and Monfort, 1990, pp.368) that $X_{i t}$ is not Granger causing $Y_{i t}$ if and only if all cross-correlations at positive lags between $u_{i t}$ and $v_{i t}$ are equal to zero. So, with $\rho_{v_{i} u_{i}}(k)=\operatorname{corr}\left(u_{i t}, v_{i t+k}\right)$ :

$$
H_{0}: X_{i t} \nRightarrow Y_{i t} \Leftrightarrow \rho_{v_{i} u_{i}}(k)=0 \text { for } k=1,2,3, \ldots
$$


where $\nRightarrow$ means "does not Granger cause". Note that one could also test for the presence of feedback relationships between $X_{i t}$ and $Y_{i t}$ by considering the cross-correlations at negative lags between $u_{i t}$ and $v_{i t}$ instead (see e.g. Sims, 1972).

The bivariate cross-correlations are estimated as

$$
\hat{\rho}_{v_{i} u_{i}}(k)=\frac{\sum_{t=1}^{T-k} \hat{u}_{i t} \hat{v}_{i t+k}}{\left(\sum_{t=1}^{T} \hat{u}_{i t}^{2}\right)^{\frac{1}{2}}\left(\sum_{t=1}^{T} \hat{v}_{i t}^{2}\right)^{\frac{1}{2}}} .
$$

If the null hypothesis of no Granger causality holds, $\hat{\rho}_{v_{i} u_{i}}(k)$ should be close to zero for all positive lags. A test statistic for the hypothesis of no Granger causality is then provided by Haugh (1976):

$$
Q_{M}=T \sum_{k=1}^{M}\left(\hat{\rho}_{v_{i} u_{i}}(k)\right)^{2} \backsim \chi_{M}^{2},
$$

where $\chi_{M}^{2}$ is a Chi-square distribution with $M$ degrees of freedom. For a pre-specified value of $M$ (here, the square root of the length of the series), $Q_{M}$ is computed and the hypothesis of no Granger causality is rejected if $Q_{M}>\chi_{M, 1-\alpha}^{2}$, where $\chi_{M, 1-\alpha}^{2}$ is the $(1-\alpha)$ quantile of the Chi-square distribution with $M$ degrees of freedom.

\subsection{Multivariate Granger-causality tests}

Let $X_{t}$ and $Y_{t}$ be two multivariate time series, $X_{t} \in \mathbb{R}^{d_{1}}$ and $Y_{t} \in \mathbb{R}^{d_{2}}$. In our case, $d=d_{1}=d_{2}$, the number of EU countries under consideration. In a first step, the multivariate time series $X_{t}$ and $\nabla^{12} Y_{t}$ are modelled separately, using Vector Autoregressive (VAR) models, i.e.

$$
\begin{aligned}
X_{t} & =C^{x}+\Phi_{1}^{x} X_{t-1}+\Phi_{2}^{x} X_{t-2}+\ldots+\Phi_{\rho_{x}}^{x} X_{t-\rho_{x}}+U_{t} \\
\nabla^{12} Y_{t} & =C^{y}+\Phi_{1}^{y} \nabla^{12} Y_{t-1}+\Phi_{2}^{y} \nabla^{12} Y_{t-2}+\ldots+\Phi_{\rho_{y}}^{y} \nabla^{12} Y_{t-\rho_{y}}+V_{t},
\end{aligned}
$$

with $U_{t}$ and $V_{t}$ two, possibly correlated, multivariate white-noise series, $U_{t} \in \mathbb{R}^{d_{1}}$ and $V_{t} \in \mathbb{R}^{d_{2}}$. The order of each VAR model is determined by the SBIC (Schwartz Bayesian 
Information) Criterion. Furthermore, $C^{x}$ and $C^{y}$ are deterministic components; $\Phi_{i}^{x}$ and $\Phi_{j}^{y}$ are autoregressive polynomials, $\Phi_{i}^{x} \in \mathbb{R}^{d_{1} \times d_{1}}$ for $i=1, \ldots, \rho_{x}$ and $\Phi_{j}^{y} \in \mathbb{R}^{d_{2} \times d_{2}}$ for $j=1, \ldots, \rho_{y}$. We denote:

$$
U_{t}=\left(\begin{array}{c}
u_{1, t} \\
\vdots \\
u_{d_{1}, t}
\end{array}\right) \text { and } V_{t}=\left(\begin{array}{c}
v_{1, t} \\
\vdots \\
v_{d_{2}, t}
\end{array}\right)
$$

Note that the series $U_{t}$ obtained after filtering with a VAR model are likely to differ from the series obtained by filtering each individual component of $X_{t}$ through univariate models. Indeed, the innovations $U_{t}$ obtained from (5) are independent of the past of every single component of $X_{t}$. With a univariate filtering procedure, in contrast, the innovation series from the first series may still carry information related to the past of the other series of $X_{t}$. Such indirect effects among the components of the $X_{t}\left(\right.$ or $\left.\nabla^{12} Y_{t}\right)$ vector are filtered out in the VAR-based approach of (5).

The estimated innovations $U_{t}$ and $V_{t}$ are cross-correlated at various leads and lags:

$$
\hat{R}^{V U}(k)=\operatorname{CORR}\left(\hat{U}_{t}, \hat{V}_{t+k}\right)=\left(\begin{array}{cccc}
\hat{\rho}_{v_{1} u_{1}}(k) & \hat{\rho}_{v_{1} u_{2}}(k) & \ldots & \hat{\rho}_{v_{1} u_{d_{1}}}(k) \\
\vdots & & & \vdots \\
\hat{\rho}_{v_{d_{2} u_{1}}}(k) & \ldots & \ldots & \hat{\rho}_{v_{d_{2} u_{d_{1}}}}(k)
\end{array}\right) \in \mathbb{R}^{d_{2} \times d_{1}}
$$

with $k=\ldots,-2,-1,0,1,2, \ldots$

The corresponding auto-correlations are defined as

$$
\hat{R}^{U U}(k)=\operatorname{CORR}\left(\hat{U}_{t}, \hat{U}_{t+k}\right) \in \mathbb{R}^{d_{1} \times d_{1}}, \hat{R}^{V V}(k)=\operatorname{CORR}\left(\hat{V}_{t}, \hat{V}_{t+k}\right) \in \mathbb{R}^{d_{2} \times d_{2}} .
$$

Since the two series of innovations $U_{t}$ and $V_{t}$ are multivariate white noise, we know that $R^{U U}(k)=0=R^{V V}(k)$ for any $k \neq 0$.

Similar to (2), one can prove (see Gouriéroux and Monfort, 1990, pp.369-370) that

$$
H_{0}: X_{t} \nRightarrow Y_{t} \Leftrightarrow R^{V U}(k)=0 \text {, for all } k>0 .
$$


A test-statistic for the hypothesis of no Granger causality was proposed by El Himdi and Roy (1997). This test looks, for every $k=1, \ldots, M$ where $M$ equals the maximum lag (again, the square root of the length of the series) at the vector:

$$
\operatorname{vec} \hat{R}^{V U}(k)=\left(\begin{array}{llllll}
\hat{\rho}_{v_{1} u_{1}}(k) & \hat{\rho}_{v_{2} u_{1}}(k) & \ldots & \hat{\rho}_{v_{1} u_{2}}(k) & \ldots & \hat{\rho}_{v_{d_{2}} u_{d_{1}}}
\end{array}\right)^{t}
$$

i.e. the correlation matrix $\hat{R}^{V U}(k)$ is vectorised into a vector of length $d_{1} d_{2}$. Under the null hypothesis, all components of this vector should be small. Note though, that not all components are independent of each other. Indeed, one can show that, under the null hypothesis and for $k>0$,

$$
\operatorname{cov}\left(\hat{\rho}_{v_{i} u_{j}}^{(k)}, \hat{\rho}_{v_{i^{\prime}} u_{j^{\prime}}}^{(k)}\right) \approx \frac{R^{v v}(0)_{i i^{\prime}} R^{u u}(0)_{j j^{\prime}}}{T},
$$

with $1 \leq i, i^{\prime} \leq d_{2}$ and $1 \leq j, j^{\prime} \leq d_{1}$ and $\approx$ standing for asymptotical equivalence.

Using this vector, one can compute (similar to (4)) the following multivariate teststatistic:

$$
Q_{H R}^{k}=T\left[\operatorname{vec} \hat{R}^{V U}(k)\right]^{t} A^{-1}\left[\operatorname{vec} \hat{R}^{V U}(k)\right],
$$

where $A$ is the asymptotic covariance matrix of $\sqrt{T}$ vec $\hat{R}^{V U}(k)$, so $A=\hat{R}^{V V}(0) \otimes$ $\hat{R}^{U U}(0)$, with $\otimes$ the Kronecker product. The values of $Q_{H R}^{k}$ can be plotted against $k$, giving an idea about the strength of the cross-correlation at various lags. The above quadratic form follows a $\chi_{d_{1} d_{2}}^{2}$ distribution under the null hypothesis, leading to the El Himdi - Roy (1997) test-statistic:

$$
Q_{H R}=\sum_{k=1}^{M} Q_{H R}^{k} \sim \chi_{M d_{1} d_{2}}^{2} .
$$

This multivariate procedure provides a more powerful test than the bivariate analogues of Section 2.1. This power gain is derived from two sources. First, all countries are pooled to find evidence of Granger causality. Moreover, it automatically permits to look for Granger causality across countries, meaning that we already allow for the possibility that the PEXP in one country Granger causes the $P A C C$ in another country. El 
Himdi and Roy (1997) applied this multivariate test to investigate the causal relations between money (M1 and M2) and income (Gross National Product) for Canada, as well as to study the causal directions between the Canadian and American economies.

Knowing the predictive content of PEXP in all considered EU countries together, one could wonder whether part of this causality can be attributed to cross-country influences. This is a natural extension of the bivariate cross-country analysis of Section 2.1. To test whether the joint cross-country causality is significant, we state the following null hypothesis:

$$
H_{0}: \tilde{R}^{V U}(k)=0 \text { for all } k>0
$$

where $\tilde{R}^{V U}(k)$ is equal to $R^{V U}(k)$ without the elements on the diagonal, yielding a $d_{1} \times\left(d_{1}-1\right)$ matrix.

The test statistic is adjusted accordingly to:

$$
Q_{H R}^{\text {cross }}=T \sum_{k=1}^{M}\left[\operatorname{vec} \widehat{\widetilde{R}}^{V U}(k)\right]^{t} \tilde{A}^{-1}\left[\operatorname{vec} \widehat{\widetilde{R}}^{V U}(k)\right]
$$

which is $\chi_{M d_{1}\left(d_{1}-1\right)}^{2}$ distributed, where $\tilde{A}$ is the asymptotic covariance matrix of $\sqrt{T} \operatorname{vec} \widehat{\tilde{R}}^{V U}(k), \tilde{A}=\widehat{\tilde{R}}^{V V}(0) \otimes \widehat{\widetilde{R}}^{U U}(0)$. In fact, $\tilde{A}$ is simply equal to $A$, from which the rows and columns corresponding to the diagonal elements of $R^{V U}(k)$ are deleted. An analogous reasoning can be applied to obtain a within-country test statistic $Q_{H R}^{\text {within }}$, which will be $\chi_{M d_{1}}^{2}$ distributed.

Finally, in order to more deeply understand the underlying interdependencies within the European Union, one could further modify the multivariate procedure to also investigate whether the PEXP series in country $i$ Granger causes the PACC of all other countries $j=1, \ldots, d, i \neq j$, and therefore offer a quantification for that country's "clout". To test for the "clout" of country $i$, only the single component $X_{i t}$ has to be taken into account to test whether the latter Granger causes the collection of all other series $Y_{j t}$, with $j \neq i$. The El Himdi - Roy procedure is then applied as outlined above, 
with $d_{1}=1$ and $d_{2}=d-1$. Similarly, we may want to test whether the $P A C C$ series of a given country $j$ is Granger caused by the PEXP of all other countries $i=1, \ldots, d$, $i \neq j$, giving a measure of the "receptivity" of country $j$. In this case, $d_{1}=d-1$ and $d_{2}=1$. In both cases, the distribution of the test statistic is a $\chi_{(d-1) M}^{2}$.

\section{DATA}

The Production Expectations PEXP series are provided by the Directorate General Economy and Finance of the European Commission. ${ }^{1}$ They are by definition subjective, reflecting the respondents' optimism/pessimism w.r.t. the evolution of the production (excluding construction). They are expressed in Balance $(\mathrm{Bal}=\mathrm{Pos}-\mathrm{Neg})$. Specifically, one asks the responding firms whether they expect their production to increase, decrease or remain unchanged over the next three months, and subsequently subtracts all decrease $(\mathrm{Neg})$ answers - in percentage points of total answers - from the percentage of increase (Pos) ones. A directional questionnaire is used as directions of change have been found to be easier to predict than point values (Jonung, 1986). Balance data were also used in Bergström (1995) and Lindström (2000), among others. ${ }^{2}$ Note, however, that problems with balance data may arise when positive and negative answers are not symmetrically distributed around zero (Entorf, 1993; Öller, 1990).

The Production Account PACC series are the monthly Industrial Production Indices reported in the OECD's publication, Main Economic Indicators. ${ }^{3}$ These production indices are collected by the OECD from the different national institutions and are expressed as an index with 1995 scaled as base index 1 (at constant prices). Industrial production includes mining, manufacturing and production of electricity, gas and water, excluding construction (compatible with ISIC Rev.3).

We selected twelve EU countries out of the (before 2004) member states: Austria, Belgium, Denmark, Finland, France, Germany, Greece, Ireland, Italy, Luxembourg, 
The Netherlands and the United Kingdom. Three countries (Portugal, Spain and Sweden) were not withheld, as this would have resulted in the loss of multiple data points due to missing observations, since monthly surveys in these countries began later. However, the twelve retained EU countries represent over $85 \%$ of the Gross Domestic Product of the EU15 in 2002 (at current prices and exchange rates). All time series are collected on a monthly basis. The data range from January 1985 to December 2002, resulting in 216 monthly observations. As, among other remarkable events, Germany's reunification took place during the considered time span, we also examined the existence of structural breaks in the time series. According to standard CUSUM tests based on recursive least squares, structural stability was found to be plausible during the whole time period, and no structural dummies were included.

A visual inspection of the raw time series (see Figure 1) reveals some apparent similarities in the $P A C C$ series among various member countries. Several of the series show a pronounced upward trend, but suffered from a temporary slowdown in the early 1990s (see e.g. the graphs for Belgium, Finland, France, Germany and the United Kingdom, among others). Still, this slowdown was much less pronounced in countries like Denmark and The Netherlands, and even less so in Ireland. Note that the Irish $P A C C$ exhibit an curvilinear trend. ${ }^{4}$

[Figure 1]

Also in the PEXP series (see Figure 2), some similarities seem to be present (see in this respect the graphs for Belgium, France and Germany), while countries like Ireland and Denmark seem to follow a more idiosyncratic evolution.

[Figure 2]

In sum, this preliminary visual inspection suggests that (i) some cross-country 
commonalities and influences could well be present, but that (ii) this will probably not be homogeneous across all member states.

\section{RESULTS}

\subsection{Bivariate within-country predictive content in Europe}

Traditionally, the within-country forecasting value of the PEXP series was assessed by bivariate causality tests. This results, in our setting, in twelve tests, whose $p$-values are reported in Table 1.

\section{[Table 1]}

The findings confirm our earlier observation that the evidence is mixed concerning the within-country predictive content of PEXP, even though some strong Granger causalities clearly appear in the table. Indeed, the null hypothesis of no Granger causality is rejected for 7 of the 12 countries at the $5 \%$ level. In line with Teräsvirta (1986), we find a significant predictive content for the Finnish PEXP series $(p=0.000)$. Note, however, that this result cannot be generalized to all Scandinavian countries, as the null hypothesis could not be rejected for Denmark $(p=0.193)$. This was also the case for Ireland $(p=0.189)$ and the United Kingdom $(p=0.132)$.

\subsection{Bivariate cross-country predictive content in Europe}

The possibility that PEXP may influence not only the own $P A C C$ series, but also (some) other countries' can be formally investigated by running an additional 132 bivariate Haugh tests, as summarized in the off-diagonal elements of Table 2. A value situated in the $i^{\text {th }}$ row and $j^{\text {th }}$ column of Table 2 represents the $p$-value for the test that the PEXP in country $i$ Granger causes PACC in country $j$. Note that, because 
of the multiple-testing issue explained below, we test at a stricter significance level of $1 \%$.

[Table 2]

In line with our earlier discussion on the dominant role of the German economy, more than predicting its own $P A C C$, German $P E X P$ also Granger causes $P A C C$ changes in several other countries, i.e. in Belgium, Finland, France and The Netherlands (at the 1\% level). A similar "clout" can be attributed to France and Belgium. The former result is not surprising, as France and Germany are often seen as two of the key forces (both economically and politically) of the European unification. The latter finding, in turn, may be linked to Belgium's central role in the location of the European Union's administration.

The British PEXP, in contrast, does not Granger cause any other country's PACC at the $1 \%$ probability level, not even its own. Even if this result cannot be overstated, it could reflect the distinct position of the United Kingdom in terms of geography, economy and culture (see Northcott, 1995 for a more elaborate discussion).

Note further that Table 2 is not symmetric. Consider, for example, Luxembourg. Its PEXP series is not informative for the future evolution of the $P A C C$ series of its neighboring Belgium, while that country's PEXP series Granger causes the PACC series of Luxembourg.

Even though the aforementioned examples provide some face validity to the figures of Table 2, it is obvious that the interpretation of that many test results is quite cumbersome, and may, not surprisingly, lead to some apparent "anomalies". For example, it is not immediately clear why PEXP in Luxembourg would Granger cause PACC in Greece, but not in its neighbouring, and culturally and economically more similar, Belgium. Moreover, even though 20 of the 132 off-diagonal $p$-values turned out to be 
smaller than 0.01, one should keep in mind that the $p$-values in Table 2 may suffer from the multiple-testing problem, and be biased downwards (Bauer, Hommel, and Sonnemann, 1988). Therefore, the predictive power of the PEXP surveys is likely to be lower than what might be inferred from Table 2. A multivariate extension of the bivariate Granger-causality tests can address these concerns.

\subsection{Multivariate European predictive content}

The El Himdi - Roy (HR) test for the null hypothesis of no Granger causality between $P E X P$ and $P A C C$ at the joint European level resulted in a test statistic $Q_{H R}$ $=2687.760$, with associated $p$-value $=0.000$. The multivariate test procedure therefore established that, in combination, the twelve PEXP series from the European Business Surveys' program have predictive value in forecasting the actual $P A C C$ series, thereby offering further justification for their continued use.

In order to get insight into the distribution of the predictive content of PEXP over time, we also consider the strength of the cross-correlation at lag $k$ as measured by $Q_{H R}^{k}$, the $k^{t h}$ term of the test statistic $Q_{H R}$, defined in (12). In Figure 3, the values of $Q_{H R}^{k}$ are plotted with respect to the lag length, and compared with the marginal critical value $\chi_{d_{1} d_{2}, 1-\alpha}^{2}$, as in El Himdi and Roy (1997).

[Figure 3]

Figure 3 illustrates that the predictive content of the PEXP slowly decreases over time, and completely drops under the significance cut-off after a few years.

\subsection{Multivariate cross-country predictive content in Europe}

When testing for the joint nullity of all cross-correlations at positive lags (14), we obtain $Q_{H R}^{\text {cross }}=2390.276$ (with $132 \times M$ degrees of freedom), with associated $p$-value 
$=0.000$, and $Q_{H R}^{\text {within }}=230.793$ (with $12 \times M$ degrees of freedom), with associated $p$ value $=0.000$. This implies that cross-country influences clearly exist, and contribute to the high combined predictive content of PEXP series in Europe.

\subsection{Multivariate clout and receptivity in Europe}

Table 3 reports the results of the tests assessing the "clout" and the "receptivity" of each of the twelve EU countries. The second column provides the $p$-value for testing the Granger causality of the PEXP in the country mentioned in the first column on all other countries' $P A C C$ series. The smaller this value, the higher the "clout" of the country. The third column of Table 3 represents the $p$-value related to the test for Granger causality of the $P E X P$ in all other countries on the $P A C C$ in that specific country. The smaller this value, the higher the "receptivity" of the country.

[Table 3]

First of all, we may observe that only the PEXP series of Germany and France have highly significant predictive content (in the multivariate Granger sense) on future $P A C C$. These findings are in line with our previous bivariate analysis, and confirm common intuition that those two economies are two key economic drivers of the European integration. The economic climate in those countries (as reflected in their balance scores on the PEXP series) is found to Granger cause the subsequent actual production in the rest of the European Union, which offers further justification for the quite large sample $\operatorname{sizes}^{5}$ (and hence higher costs of data collection) in those countries' Business Tendency Surveys. In contrast, Germany has a low "receptivity" score: while it drives the European Union, it is less likely to be influenced by the other member countries.

Another key fact illustrated by the multivariate test is that many countries have no significant "clout", not even at very liberal significance levels; see e.g. Austria 
$(p=0.889)$, Denmark $(p=0.810)$, Ireland $(p=0.345)$, Italy $(p=0.812)$, and the United Kingdom $(p=0.533)$. This suggests that the highly significant multivariate predictive content of the PEXP series will be mainly driven by a few key countries such as France and Germany. One could even question the usefulness of a continued use of the Business Tendency Surveys in countries like Denmark, Ireland or the United Kingdom, as they do not have a significant predictive power for the actual economic evolution in the other member countries (Table 3), nor for their own actual economic evolution (cf. Table 1). The latter conclusion is, however, conditional on the analyzed PEXP and PACC series. As indicated in Section 1, the Business Tendency Surveys also collect data on other components of the economy such as retail trade, services, construction..., and more research is necessary to assess whether this conclusion also holds in these other domains.

In terms of the "receptivity", we find a significant $(p<0.05)$ effect for three countries: Austria, Denmark and Finland. Our findings for Denmark are in line with Putsis et al. (1997), who showed that this country derives a higher percentage of its contacts from outside its borders than internal. This corroborates the fact that Denmark has low within-country predictive power $(p=0.193)$, while having high "receptivity" $(p=0.029$; Table 3$)$. As for Austria and Finland, more than $60 \%$ of the total trade of these former EFTA countries is directed towards the EU (Sapir, 1998), which may well explain their high receptivity scores.

Finally, it is worth noting that the United Kingdom and Ireland score low on both dimensions. This may reflect their geographically distinct position, but also - at least for the United Kingdom - the country's relative distinctiveness in terms of economic integration and culture (Northcott, 1995). The low "receptivity" and "clout" of Ireland, in turn, is in line with the pan-European study of Mahajan and Muller (1994), who found the Irish population to be much less sensitive to word-of-mouth influences, which is a key mechanism through which cross-country PEXP may influence future $P A C C$ 
levels.

\section{CONCLUSIONS}

Each month, for over forty years, the European Union, together with institutions from the fifteen member states of the European Union, carries out costly and timeconsuming Business Tendency Surveys on the past, actual and future state of the European Economy. Since they are, on a regular basis, used for economic surveillance by several parties, there is a concern about their performance in predicting actually realized Account data, especially since existing literature on the topic offers mixed evidence on the Surveys' predictive content.

In this paper, we tested the Granger causality between $P E X P$ and $P A C C$ series from twelve European countries. Instead of only focusing on a sequence of bivariate within-country analyses, we also undertook a simultaneous, multivariate approach. Indeed, when predicting the future production level in a country, there is no reason to a priori ignore the information conveyed by Business Surveys in other countries. In this sense, the predictive content of PEXP series could be evaluated both at the national (bivariate test) and at the European (multivariate test) level.

While confirmation of Granger causality at the individual country level was not found for every country - seven countries out of twelve showed a significant predictive content at the $5 \%$ level - , very strong evidence of Granger causality was discovered at the multi-country level. It also turned out that the cross-country Granger causalities were jointly strongly significant, indicating that it could indeed be advantageous to exploit these correlations in multivariate forecast methods.

Moreover, according to the multivariate analysis, some countries (i.e. France and Germany) have more "clout" than others, while others are more "receptive" (i.e. Aus- 
tria, Finland and Denmark). Finally, the United Kingdom and Ireland seem to occupy a fairly isolated position. They both have no "clout" and no "receptivity".

As a conclusion, we state that the harmonization of European Business Tendency Surveys allows to exploit cross-country relations between the different series and to improve forecasts of future Account data for an individual country by using a multivariate approach. More research is open to generalize these findings to other variables that are routinely collected in the EU Business Tendency Surveys.

\section{Acknowledgements}

The authors would like to thank the "Fonds voor Wetenschappelijk Onderzoek" and the Research Fund K.U.Leuven (contract numbers G.0116.04 en G.0385.03 ) for financial support. We also wish to especially thank the editors and referees of this journal for their helpful comments.

\section{References}

[1] Artis, M.J., and Zhang, W. (1997). International Business Cycle and the ERM: Is there a European Business Cycle?, Journal of Finance and Economics, 2, 1-16.

[2] Artis, M.J., and Zhang, W. (1999). Further Evidence on the International Business Cycle and the ERM: Is there a European Business Cycle?, Oxford Economic Papers, 51, 120-132.

[3] Bauer, P., Hommel, G. and Sonnemann, E. (1988). Multiple hypotheses testing, Berlin: Springer. 
[4] Bergström, R. (1995). The Relationship between Manufacturing Production and Different Business Survey Series in Sweden 1968-1992, International Journal of Forecasting, 11, 379-393.

[5] Buffeteau, S. and Mora, V. (2000). Predicting the National Accounts of the Euro Zone using Business Surveys, INSEE Conjuncture in France, December.

[6] Christoffersson, A., Roberts, R. and Eriksson U.(1992). The Relationship between Manufacturing and Various Business Tendency Survey Series in Sweden Illuminated by Frequency and Complex Demodulate Methods, NIER Working Paper Stockholm, 15.

[7] Cooper, L.G. and Nakanishi, N. (1998). Market-Share Analysis, Massachusetts: ISQM Kluwer Academic Publishers.

[8] El Himdi, K. and Roy, R. (1997). Tests for Non-Correlation of two Multivariate ARMA Time Series, The Canadian Journal of Statistics, 25, 233-256.

[9] Entorf, H. (1993). Constructing Leading Indicators from non-Balanced Sectoral Business Surveys Series, International Journal of Forecasting, 9, 211-225.

[10] Gouriéroux, Ch. and Monfort, A. (1996). Time Series and Dynamic Models, Glasgow: Cambridge University Press.

[11] Granger, C.W.J. (1969). Investigating Causal Relations by Econometric Models and Cross-Spectral Methods, Econometrica, 37, 424-438.

[12] Granger, C.W.J. (1980). Forecasting in Business and Economics, New York: Academic Press.

[13] Hanssens, D.M. and Vanden Abeele, P.M. (1987). A Time-Series Study of the Formation and Predictive Performance of EEC Production Survey Expectations, Journal of Business and Economic Statistics, 5, 507-519. 
[14] Haugh, L.D. (1976). Checking the Independence of two Covariance-Stationary Time Series: a Univariate Residual Cross-Correlation Approach, Journal of the American Statistical Association, 71, 378-385.

[15] Klein, P.A. and Moore, G.H. (1983). The Leading Indicator Approach to Economic Forecasting - Retrospect and Prospect, Journal of Forecasting, 2, 119-135.

[16] Jonung, L. (1986). Uncertainty about Inflationary Perceptions and Expectations, Journal of Economic Psychology, 7, 315-325.

[17] Lindström, T. (2000). Qualitative Survey Responses and Production over the Business Cycle, Central Bank of Sweden - Working Paper Series, 116, November.

[18] Mahajan, V. and Muller, E. (1994). Innovation Diffusion in a Borderless Global Market: Will the 1992 Unification of the European Community Accelerate Diffusion of New Ideas, Products, and Technologies?, Technological Forecasting and Social Change, 45, 221-235.

[19] Northcott, J. (1995). The Future of Britain and Europe, London Policy Studies Institute Research Report, 776.

[20] Öller, L.-E. (1990). Forecasting the Business Cycle Using Survey Data, International Journal of Forecasting, 6, 453-461.

[21] Öller, L.-E. and Tallbom, C. (1996). Smooth and Timely Business Cycle Indicators for Noisy Swedish Data, International Journal of Forecasting, 12, 389-402.

[22] Putsis, W.P., Balasubramanian, S., Kaplan E.H. and Sen, S.K. (1997). Mixing Behavior in Cross-Country Diffusion, Marketing Science, 16, 354-369.

[23] Sapir, A. (1998). The Political Economy of EC Regionalism, European Economic Review, 42, 717-732. 
[24] Sensier, M., Artis, M., Osborn, D.R. and Birchenhall, C. (2004). Domestic and International Influences on Business Cycles Regimes in Europe, International Journal of Forecasting, 20, 343-357.

[25] Sims, C.A. (1972). Money, Income, and Causality, The American Economic Review, 62, 540-552.

[26] Tellis, G.J., Stremersch, S. and Yin E. (2003). The International Takeoff of New Products: The Role of Economics, Culture and Country Innovativeness, Marketing Science, 22, 188-208.

[27] Teräsvirta, T. (1986). Model Selection with Business Survey Data: Forecasting the Output of Finnish Metal and Engineering Industries, International Journal of Forecasting, 2, 191-200.

\section{Notes}

${ }^{1}$ The data are publicly available on http://europa.eu.int/comm/economy_finance/ indicators/businessandconsumersurveys_en.htm

${ }^{2}$ For an in-depth discussion on the relative merits of such balance indicators, see e.g. Granger (1980, ch.7), Klein and Moore (1983) or Hanssens and Vanden Abeele (1987).

${ }^{3}$ We refer to http://www.oecd.org/std/mei for more details. Note that the PACC series differ from the so-called National Accounts, which typically are quarterly data.

${ }^{4} \mathrm{~A}$ log-transform of the Irish series was considered, and found not affecting the results.

${ }^{5}$ According to "The Joint Harmonised EU Programme of Business and Consumer Surveys User Guide 2002", France and Germany together represent more than 25\% of the industry-related surveyed units across the European Union. 


\section{Tables and Figures}

Table 1: $p$-values of the Haugh test for assessing whether PEXP of a selected country Granger causes $P A C C$ in the same country.

\begin{tabular}{|l|l|}
\hline Country & $p$-value \\
\hline Austria & $0.008^{*}$ \\
Belgium & $0.003^{*}$ \\
Denmark & 0.193 \\
Finland & $0.000^{*}$ \\
France & $0.000^{*}$ \\
Germany & $0.001^{*}$ \\
Greece & 0.080 \\
Ireland & 0.189 \\
Italy & $0.001^{*}$ \\
Luxembourg & $0.013^{*}$ \\
The Netherlands & 0.057 \\
The United Kingdom & 0.132 \\
\hline
\end{tabular}

* significant at the $5 \%$ probability level. 


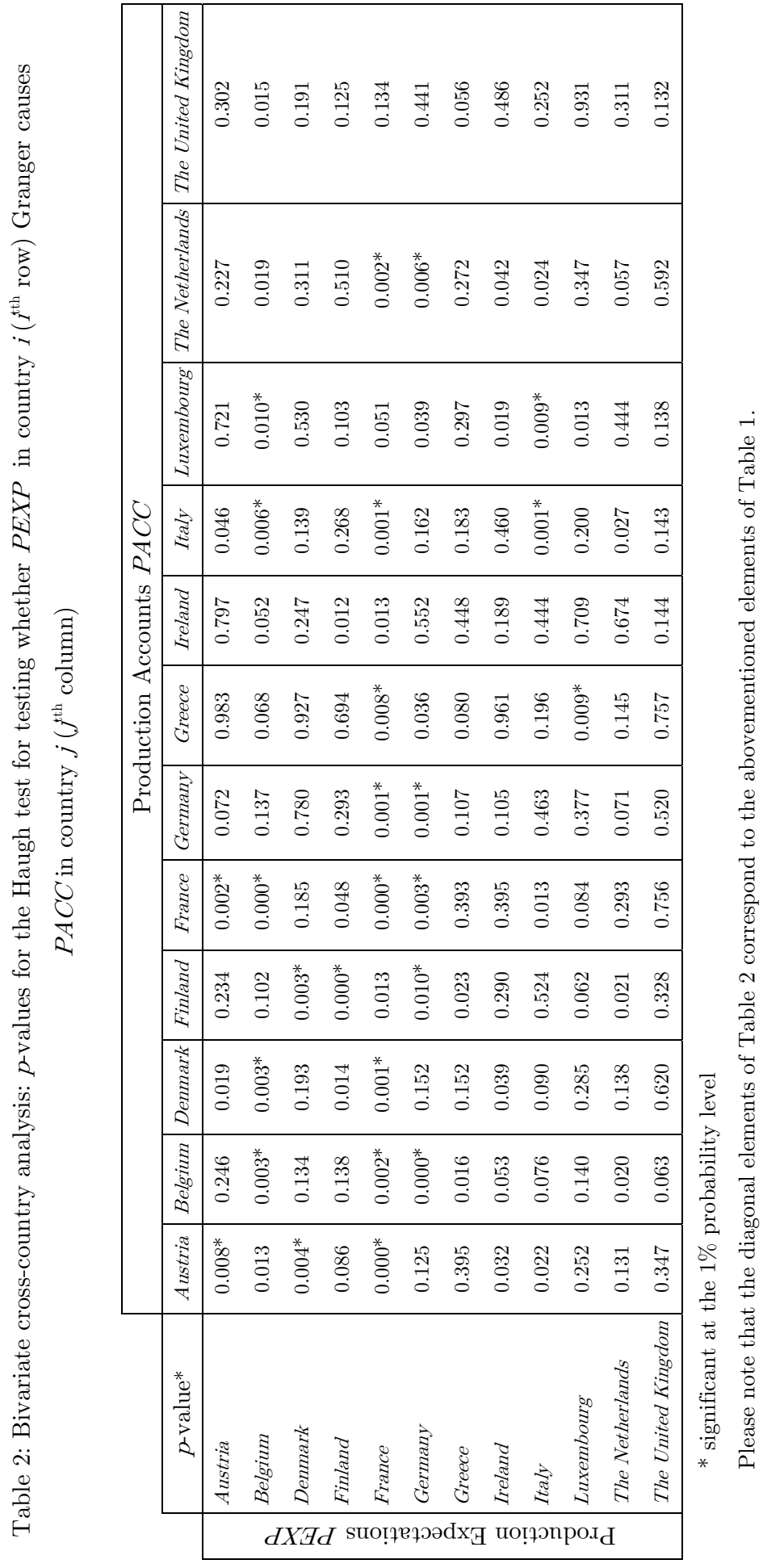


Table 3: $p$-values of the El Himdi - Roy test for assessing the "clout" and the "receptivity" of a selected country.

\begin{tabular}{|l|l|c|}
\hline Country & Clout & Receptivity \\
\hline Austria & 0.889 & $0.005^{*}$ \\
Belgium & 0.058 & 0.159 \\
Denmark & 0.810 & $0.029^{*}$ \\
Finland & 0.122 & $0.028^{*}$ \\
France & $0.000^{*}$ & 0.052 \\
Germany & $0.004^{*}$ & 0.427 \\
Greece & 0.096 & 0.253 \\
Ireland & 0.345 & 0.476 \\
Italy & 0.812 & 0.250 \\
Luxembourg & 0.098 & 0.148 \\
The Netherlands & 0.156 & 0.357 \\
The United Kingdom & 0.533 & 0.796 \\
\hline
\end{tabular}

* significant at the $5 \%$ probability level. 

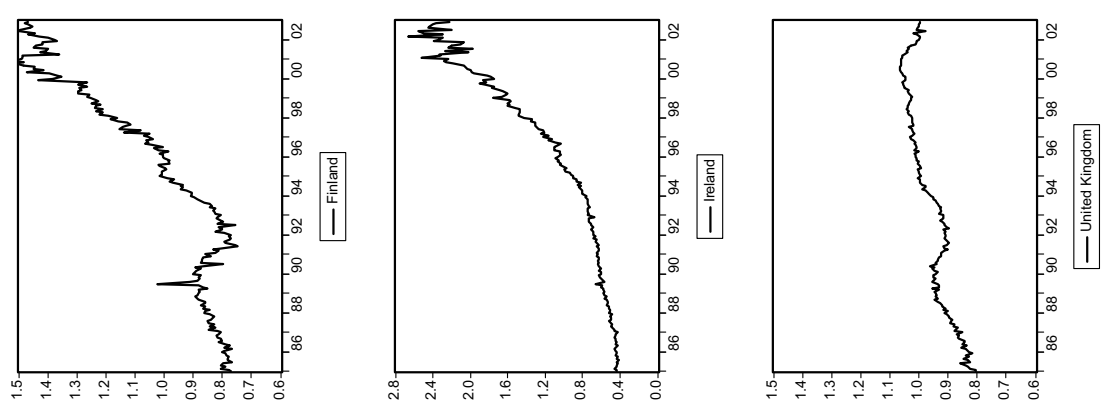

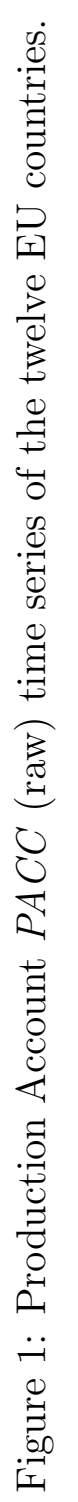
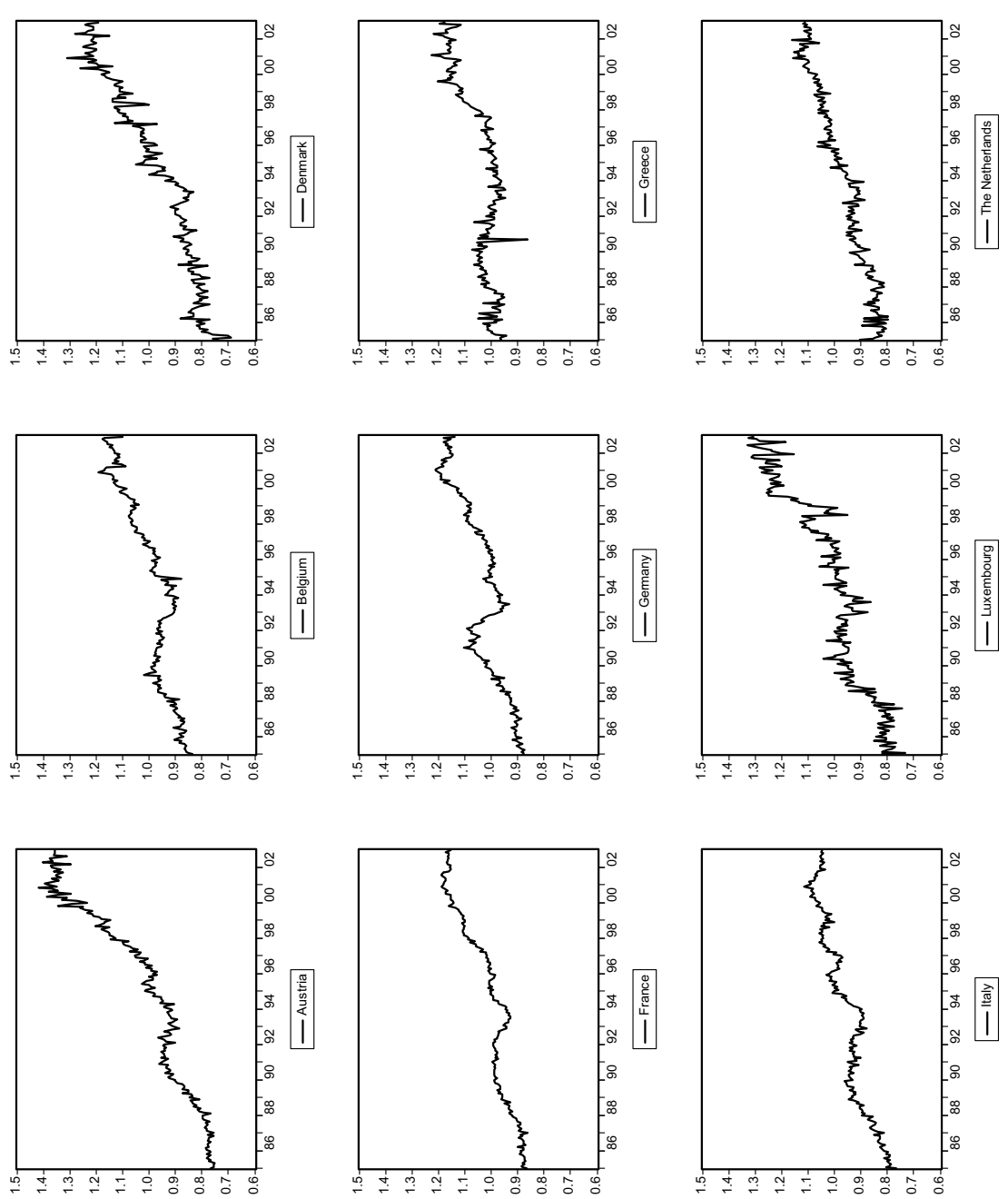

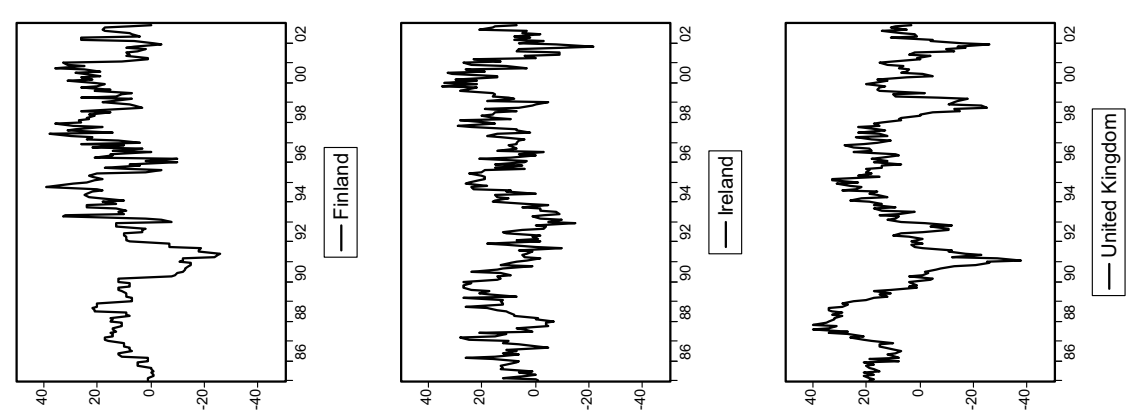

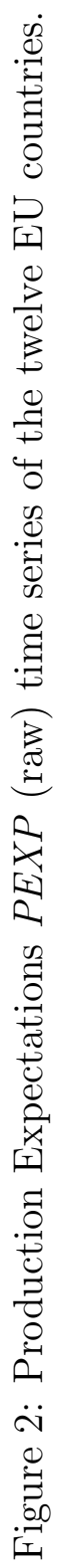
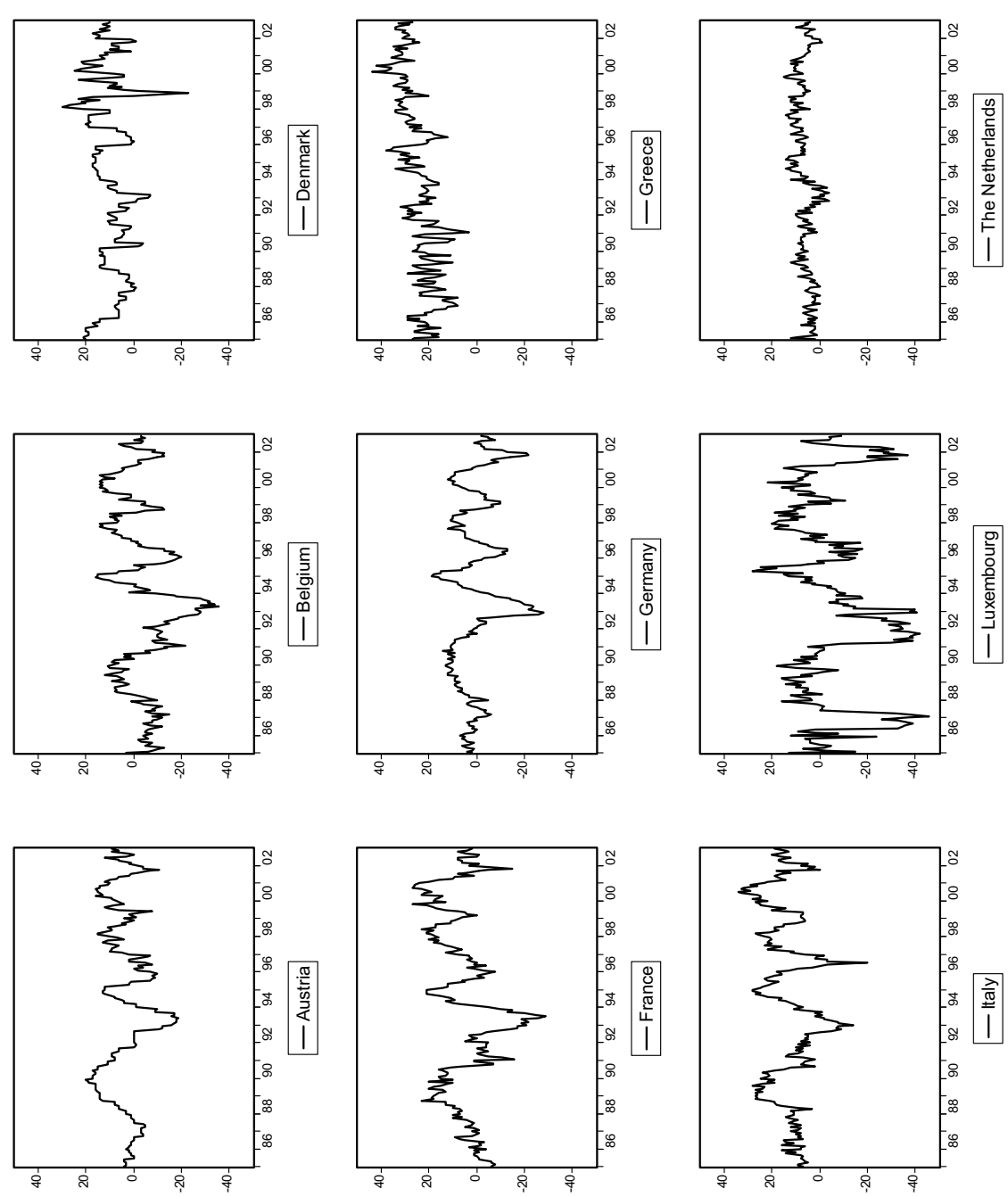
Figure 3: Measure $Q_{H R}^{k}$ of multivariate Granger causality of $P E X P$ on $P A C C$, for lags up to $k=100$ months.

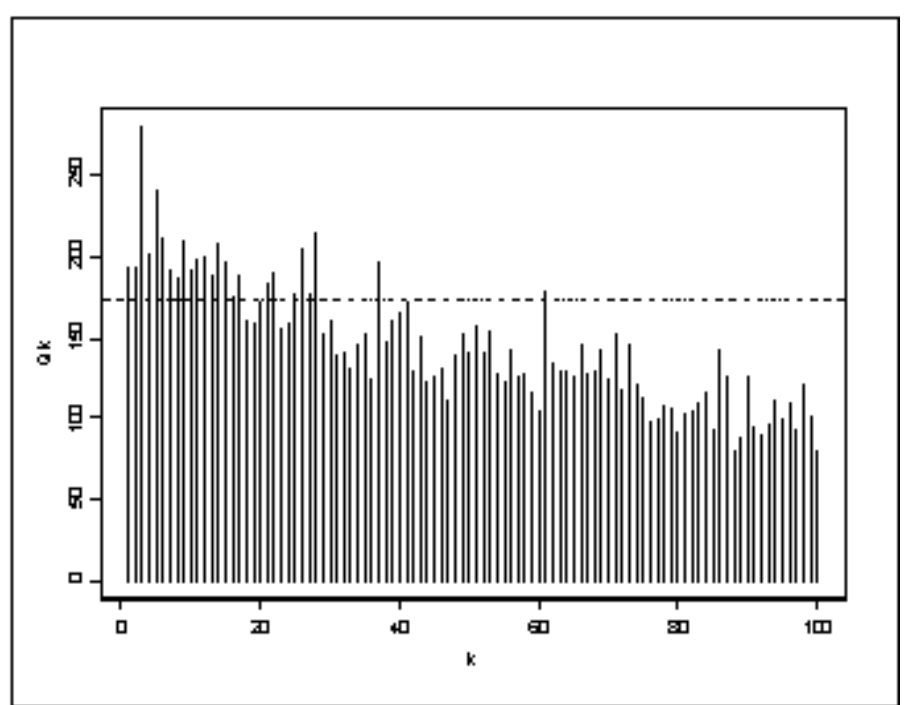

